FOLIA SCANDINAVICA VOL. 24 POZNAŃ 2018 DOI: $10.2478 / \mathrm{fsp}-2018-0004$ sciendo

PRESSto.

\title{
MELLEM DET (POST)KOLONIALE, DET (POST)NATIONALE OG DET GLOBALE: EN ANALYSE AF NIVIAQ KORNELIUSSENS HOMO SAPIENNE
}

\author{
AgATA LUBOWICKA \\ University of Gdańsk
}

ABSTRACT. The paper presents a close-reading of the Greenlandic author Niviaq Korneliussen's novel Homo sapienne (2014) with the aim of answering the question, whether it can be defined as a postnational or a migration novel, according to the definitions presented by Elisabeth Oxfeldt and Søren Frank. To this end four different categories: the hybrid, the (post)colonial, the national and the global are applied in the analysis with the primary focus on examining how the dominating narratives of Greenlandicness are confirmed, challenged or rejected in the novel, as well as how the novel's language, structure and narrative strategies not only contribute to a new understanding of the genre, but of the issues in question in general.

\section{INDLEDNING}

I sin artikel om migrationslitteratur skriver Søren Frank om en tendens i nutidig litteratur skrevet af ikke-migranter til "at afspejle temaer og anvende diskursive strategier, som vi ofte tænker på som værende typiske for migrantlitteraturen" (Frank, 2012:8). Sådanne forfattere, påstår litteraturforskeren, "formulerer en kosmopolitisk, transnational og hybrid vision om den sociale virkelighed", selv om "[t]ransnational litteratur skrives [...] ikke kun uden for nationen, men også inde fra nationen" (Frank, 2012:9). Sidstnævnte pointe om nationen er vigtig her, siden den afspejler en bredere forståelse af og en stigende interesse for forskning i bl.a. nordiske litteraturer, hvor nationen stadig udgør et vigtigt referencepunkt. Et af de mest fremtrædende eksempler er Elisabeth Oxfeldts læsninger af nutidige nationalromaner, men i et postnationalt perspektiv, hvilket lader til at være oplagt " $\mathrm{i}$ 
globariseringens, avnasjonaliseringens, internasjonaliseringens og kosmopolitismens tid" (Oxfeldt, 2012:15). Disse værker, sådan som Oxfeldt beskriver dem, er i modsætning til nationsbyggende romaner fra 1800-tallet, "kritiske, skyldbevidste og internasjonalt perspektiverte" (Oxfeldt, 2012:16). Det er iøjnefaldende, at den brede definition af migrationslitteratur, som Frank foreslår, udviser mange lighedspunkter med hvad Oxfeldt anser for særligt kendetegnende ved postnationale romaner, og begge litteraturforskere illustrerer endda deres synspunkter med samme litterære eksempler ${ }^{1}$. Et andet vigtigt fællesstræk er, at de begge bruger postkolonial teori som et væsentligt bidrag til deres perspektiver, og på den måde bliver migration, det (post)nationale og det postkoloniale koblet sammen i et uløseligt net af forbindelser og påvirkninger. Dette net vil netop danne teoretisk udgangspunkt for nedenstående analyse.

Siden Grønland fra 1979 har fået hjemmestyre, og siden 2009 været et selvstyrende område, har grønlændere som danske statsborgere ikke migrantstatus i Danmark. Dette medfører, at de som en minoritetsgruppe til en vis grad bliver overset $\mathrm{i}$ den danske indvandrerdiskurs ${ }^{2}$, men når det gælder de grønlændere, der bor i Grønland, ville det selvfølgelig være absurd at kategorisere dem som en minoritets- eller migrantgruppe. Det betyder imidlertid ikke, at indførelsen af hjemme- og selvstyre har gjort en ende på det tidligere asymmetriske magtforhold inden for selve Rigsfællesskabet, som Grønland fortsat er en del af. Af disse grunde har der i hvert fald de sidste 25 år været en tradition at betragte og analysere grønlandsk kulturproduktion ud fra en postkolonial synsvinkel. Det gælder ikke mindst litteratur, både den såkaldte grønlandslitteratur (skrevet fortrinsvis af danske forfattere og på dansk) samt litteraturen skrevet (fortrinsvis) på grønlandsk af grønlandske forfattere (Thisted, 2004:134) 3 $^{3}$ Idéen med denne artikel er at analysere den grønlandske forfatter Niviaq Korneliussens succesfulde roman HOMO sapienne for at finde ud af, om den ud fra de ovenfor opstillede teorier kan defineres som en postnational eller en migrationsroman - det vil sige en roman, der problematiserer det nationale ved at formulere en mere kosmopolitisk og hybrid vision af det grønlandske samfund, og i hvilken grad det stadigvæk er relevant at anlægge det postkoloniale perspektiv i læsninger af nutidig grønlandsk litteratur.

${ }^{1}$ Det mest fremtrædende eksempel i nordisk kontekst er Jan Kjærstads Wergeland-trilogi fra 1990erne (Oxfeldt, 2012:16; Frank, 2012:8).

${ }^{2}$ Grønlændernes migration til Danmark er blevet grundigt analyseret af Tekke Terpstra i Inuit outside the Arctic: Migration, identity and perceptions (2015).

$3 \mathrm{Om}$ forskellene mellem hovedemnerne, som disse to litteraturer nu til dags tager udgangspunkt $\mathrm{i}$, forklarer Thisted, at grønlandsk litteratur skrives med udgangspunkt i selvstændighedsproblematikken, mens dansk grønlandslitteratur skrives med udgangspunkt i dobbelt identitet, eller Rigsfællesskabsproblematikken. Oplæg om "Grønlandsk litteratur" ved arrangementet "Nye fortællinger fra Grønland - den grønlandske kulturrevolution", Århus, ARoS, 21.05.2017. 
Analysen i denne artikel er struktureret på baggrund af fire kategorier: det hybride, det (post)koloniale, det postnationale og det globale, som alle udspringer fra det samme teoretiske udgangspunkt. Inden for disse strukturelle rammer har jeg sat mig som mål at undersøge følgende tre hovedproblemer: måden, hvorpå romanen forholder sig til de gængse fortællinger om grønlandsk identitet, nationen og landets postkoloniale relation til Danmark, men derudover vil der også blive sat fokus på, hvordan den som et hybridt litterært værk, der går på tværs af forskellige mediegenrer, skriver sig ind i en mere transnational kontekst. Mens jeg derfor i de første tre afsnit vil benytte mig af redskaberne inden for repræsentationsanalyse, vil jeg i sidste afsnit anvende komparativ metode med henblik på at sammenligne HOMO sapienne med den succesfulde norske ungdomsserie $S K A M$. Formålet med sidstnævnte er at vise en mulig åbning mod andre fortolkningsmuligheder af romanen, dvs. som en del af den globale ungdomskultur inspireret af elektroniske og sociale medier, der $\mathrm{i}$ stedet for at trænge den traditionelle litteratur ud, bidrager til dens kreative udvikling.

\section{GAMLE OG NYE OG NYE FORTÆLLINGER OM GRØNLANDSK NATIONAL OG KULTUREL IDENTITET}

Med udgangspunkt i de socialkonstruktivistiske teorier om nations- og identitetsproblematikken, såsom Benedict Andersons ${ }^{5}$ og Stuart Halls ${ }^{6}$, vil jeg indledningsvis fokusere på de dominerende fortællinger om den grønlandske nation og grønlandsk national identitet, for derefter at undersøge måden, hvorpå HOMO sapienne kommer i dialog med dem: præsenterer en (implicit eller eksplicit) kritik af dem, skaber modfortællinger til dem og / eller foreslår et mere inkluderende alternativ.

Grønlandsforskeren Kirsten Thisted påpeger, at der traditionelt har eksisteret grundlæggende skematiske fortællinger (såkaldte "schematic narrative

${ }^{4}$ Disse kategorier må selvfølgelig tages med et vist forbehold, for det første fordi jeg er klar over, at de i høj grad er indbyrdes forbundet med hinanden, og for det andet fordi selve kategoriseringen uundgåeligt er med til at forenkle det analyserede materiale.

${ }^{5}$ Frem for at være en objektiv, empirisk enhed, er en nation ifølge Anderson "an imagined political community - and imagined as both inherently limited and sovereign" (Anderson, 2003:6).

${ }^{6}$ Stuart Hall definerer kulturel identitet som "a matter of 'becoming' as well as 'being'. It belongs to the future as much as to the past. It is not something which already exists, transcending place, time, history and culture. Cultural identities come from somewhere, have histories. But like everything which is historical, they undergo constant transformation. Far from being eternally fixed in some essentialised past, they are subject to the continuous 'play' of history, culture and power". (Hall, 1990:225). I dette lys forstås kulturelle, men også nationale identiteter som symbolske og ideologiske produkter, kulturelle 'performances' baseret på forestillede fællesskaber, som forbinder sprog, historie og kultur med magt. 
templates”) om Grønland og grønlændere både i den danske, den grønlandske og $\mathrm{i}$ omverdenens bevidsthed. De ældste af dem har deres rødder i den koloniale periode og blev i starten lanceret af kolonimagten, dvs. danskere, men nogle af dem blev til en vis grad senere overtaget af grønlændere selv, mens andre blev konfronteret med grønlændernes egne modfortællinger, der opstod i det 20. århundrede i takt med nationsbygningsprocessen (Thisted, 2013:230-231). I de postkoloniale fortællinger, både danske og grønlandske, blev grønlændere oftest udlagt som kolonisationens (og globaliseringens) ofre og dermed placeret i en position som passive objekter for andres ugerninger, også med hensyn til de senest opståede diskurser om den globale opvarmning. Den essentialistiske konceptualisering af grønlandsk identitet blev især fremmet i kølvandet på 70ernes politiske kamp og den senere indførelse af hjemme- og selvstyre samt nutidens til dels nationalistiske fortællinger, der blev vakt til live som følge af den politiske kurs mod selvstændighed (Pram Gad, 2009). I denne konstruktionsproces af det monokulturelle Grønland har danskere spillet rollen som grønlændernes Anden (lige som grønlænderne også har været det i konstruktionen af dansk identitet), men der er i de seneste år opstået alternative fortællinger til den essentialistisk-nationale diskurs, hvor Danmark får skylden for Grønlands offerstilling. De er primært skabt af unge grønlændere, som, utilfredse med offerrollen som følge af dansk kolonisering, foretrækker at identificere sig med det globale, der giver dem muligheden for at afprøve nye relationer og dermed forhandle deres identitetspositioner frem for fortsat at være viklet ind i de gamle dansk-grønlandske dikotomiske relationer (Thisted, 2011:602-603) ${ }^{7}$.

\section{ANALYSE AF HOMO SAPIENNE}

Niviaq Korneliussen (født i 1990 i Nuuk) er repræsentant af den unge generation blandt grønlandske forfattere, og i det hele taget en længe ventet stemme i grønlandsk litteratur ${ }^{8}$. Født efter 1979, tilhører hun den unge generation af grønlændere, som af Tine Bryld metaforisk er blevet kaldt "hjemmestyrets børn" (Bryld, 2002). Hun debuterede i en novellekonkurrence arrangeret af det grønlandske forlag Milik Publishing, NAPA, Nunatta Atuagaateqarfia for unge grønlandske forfattertalenter „Allatta / Lad os skrive!”,

\footnotetext{
${ }^{7}$ Unges holdninger er beskrevet og analyseret i Birgit Kleist Pedersens artikel „Unge og litteratur - 25 år efter” (Kleist Pedersen, 2004).

${ }^{8}$ I en artikel fra 2003 skrev litteraturforskeren Karen Langgård om, at grønlandske læsere var begyndt at stille nye krav til grønlandsk litteratur, og især "var mange unge trætte af den evige diskurs om det ægte grønlandske, som virkede meget tilbageskuende og musealt. Litteraturen skulle være mere spændende, mindre fikseret på et etnisk-nationale og tilhørende symboler, og skulle behandle deres livsproblemer, som de så ud i en moderne grønlandsk hverdag." (Langgård, 2003:290).
} 
hvor hendes novelle blev udvalgt som en af de 10 bedste og efterfølgende trykt i en tosproget antologi Allatta - Inuusuttut, Nunatsinni Nunarsuarmilu / Allatta - Ung $i$ Grønland, ung $i$ Verden i 2013 (Therkildsen, Vahl, 2013). HOMO sapienne, der udkom på grønlandsk i 2014, og derefter samme år på dansk (begge blev udgivet af Milik Publishing), var Korneliussens meget succesfulde romandebut og den er indtil videre blevet oversat til engelsk, tysk og fransk.

\subsection{DET HYBRIDE}

Når man i første omgang fokuserer på romanens mest iøjnefaldende paratekster, dvs. titlen og billedet på omslaget, bemærkes det, at de begge artikulerer en antidiskurs mod normative opfattelser af køn - og menneskelighed. Titlen HOMO sapienne dekonstruerer dem direkte ved at bruge femininumsformen af ordet homo sapiens, som afslører termens kønnede og dermed ideologiske karakter. Dette budskab bliver suppleret af det sort-hvide billede på omslaget, som forestiller en langhåret person med kvindelige ansigtstræk, dog uden synlige biologiske kønsmarkører. Personen er nøgen, har en velbygget, muskuløs krop, og befinder sig i siddende position, som leder tankerne hen på noget maskulint. Man tvinges til at gætte personens udefinerbare kønslige identitet, men bliver ved med at være i tvivl. Det lange sorte hår og nøgenheden konnoterer naturtilsand og vildhed, der gennem århundreder er blevet forbundet med grønlændere som et naturfolk, men dette indtryk modsiges af ét "fremmedelement" i fotoet - den androgyne person på omslaget er i gang med at spise en banan - en genstand, som enten henleder vores tanker på noget eksotisk og forbundet med varmere egne på kloden, eller også vækker den tydelige seksuelle associationer og skriver fotoet ind i den globale popkultur ved at bruge en af dens mest fremtrædende ikoner. Dette indtryk forstærkes af de yderligere fem sort-hvide fotografier i bogen, der lige som de fem kapitler, de hver især indleder, fletter sig ind i og supplerer hinanden.

Man konstaterer, at bogens visuelle paratekster på en spøgefuld måde gør læseren opmærksom på det glidende og grænseoverskridende, der kendetegner alle identiteter og de dertil knyttet betydninger. Når vi flytter fokus over på romanens indhold, viser det sig, at hovedtemaet ligeledes er det ikkenormative og marginale, som sætter spørgsmålstegn ved de fastlåste, dominerende kategorier af køn, men også af nationalitet. Vi bliver præsenteret for fem selvstændige og ligeværdige fortællinger, hvor unge mennesker, indbyggere $\mathrm{i}$ Grønlands hovedstad Nuuk, hver på sin vis forsøger at finde en vej ud af en vanskelig situation, de er havnet i som følge af deres (undertrykte / fortrængte) seksuelle orientering eller (undertrykte / fortrængte) følelser i almindelighed. Således læser vi forskellige historier, hvor fortællerne henholdsvis er lesbiske Fia, hendes homoseksuelle lillebror, Inuk, biseksuelle Arnaq, transseksuelle 
Ivik og lesbiske Sara. Mens Fias, Inuks og Iviks historier kan klassificeres som "coming-out stories" af forskellig art, er Arnaq og Sara for længst forsonet med deres seksuelle orientering og deres fortællinger kredser om problemer med alkoholmisbrug som følge af at være offer for seksuelle overgreb eller det at være ulykkelig i sit faste forhold.

Ved at tage udgangspunkt i Homi Bhabhas definition af det hybride rum som en kulturel overskridelse, "positioner, som ikke 'passer ind', men befinder sig 'på marginen' - hverken helt ude eller helt inde", som det formuleres af kulturforskeren Birgitta Frello (Frello, 2005:91), vil jeg undersøge, hvorvidt der er tale om sådanne "utilpassede" subjektpositioner i HOMO sapienne. I analysen vil jeg primært fokusere på hovedpersonen Inuk, Fias lillebror, som flygter fra Nuuk til København, hvorfra han som (midlertidig) migrant skriver sin fragmenterede fortælling.

Inuk er måske den mest gådefulde af hovedpersonerne i romanen. Han udtrykker sig oftest i blog-lignende indlæg underskrevet med skiftende, betydningsbærende nicknames: Flygtning 2014, Survivor, Refugee, High Jesus (sitting left to God), Løgner, CLAUSTROPHOBIC HOMOPHOBE, From nowhere, Ham, der ikke vil være grønlænder, Greenlander by force, Silent, Lost, Arbejdsløs, Ikke vred, Dead, Home, Homo.Sapiens.Inuk. Ved at analysere deres rækkefølge og indhold bemærker man en bevægelse - fra at være flygtet og faret vild til at finde sit hjem igen, så de afslører allerede på dette trin en historie om søgen efter identitet. Af Inuks fragmenterede og metaforiske fortælling fremgår det, at han er flygtet fra Grønland til Danmark på grund af et (uretfærdigt?) rygte, der har spredt sig i Nuuk, om hans bekendte Mikis homoseksualitet. Som tidligere nævnt er Inuk den eneste af hovedpersonerne i romanen, der fortæller ud fra en migrantposition, hvilket får ham til at reflektere om sin særlige "utilpassede" placering i højere grad end de andre personer: "Hvis hjem ikke er i Grønland, hvis hjem ikke er her, hvor er mit hjem så?" (Korneliussen, 2014:66). Men i modsætning til, hvad postkoloniale teoretikere påstår, medfører det ikke et både-og-perspektiv: "Jeg har utrolig meget hjemve, men ved ikke, hvad det er for mit hjem, jeg leder efter" (ibid.:70). Inuk er nemlig overbevist om, at der må findes ét hjem, dog ikke så meget $i$ et tredje sted mellem det danske og det grønlandske, for - som han til sidst indrømmer - "[d]et er pinligt at være grønlænder, men jeg er grønlænder." (ibid.:66) Som grønlænder i København oplever han, at han alligevel ikke hører til og konstaterer: "Danmark er ikke mit hjem." (ibid.). Selv om han i sine indlæg kommer med en hård kritik af Grønland og grønlændere, hvilket vil blive analyseret $\mathrm{i}$ afsnit $3 \mathrm{i}$ denne artikel, føler han stadigvæk et fast tilhørsforhold til sit hjemland.

Selv om Inuk som dansk statsborger sandsynligvis har fortroligt kendskab til den danske kontekst, er det ikke nok til at opnå et hybridt perspektiv. Hans flugt og konfrontation med det, som han alligevel ikke hører til, får ham dog til 
at indse, at det ikke er de andre (dvs. grønlændere eller danskere), der er skyld i hans problemer, men derimod ham selv. Han overskrider ikke sin kulturelle identitet, men overskrider sig selv - dvs. det selv, som ifølge Michael Foucault konstrueres og formes af normative ideologiske diskurser (Foucault, 1999:126).

Pointen ser ud til at være, at hovedpersonerne i romanen har hver sin fastlåste, bestemte seksuelle orientering, som er marginal og perifer i forhold til det heteronormative. På den måde er det svært at sige, at der opstår noget in-between - et "tredje sted", for at bruge Bhabhas terminologi - mellem det danske og grønlandske, eller mellem de forskellige - faste, ikke flydende seksuelle identiteter, der tilbydes. Personernes rolle går snarere ud på at anskueliggøre det ikke-normative som det normatives konstitutive Andet, der i virkeligheden er nødvendigt for opretholdelsen af den dominerende monodiskurs. Deres tilstedeværelse i romanen modsætter sig fortællingen om Grønland som et monokulturelt og heteroseksuelt samfund og artikulerer en identitetsdiskurs, hvor også grønlændere med en anden seksuel orientering er inkluderet.

\subsection{DET (POST)POSTKOLONIALE}

Af mange anmeldere og almindelige læsere blev romanen kåret som et opgør med postkolonial tænkning, samtidigt med at være en "coming-out story". Det ligger i forlængelse af det faktum, at der er en general forventning til en roman skrevet på grønlandsk og om grønlandske forhold, om at den må forholde sig til det postkoloniale i relationen Danmark-Grønland. Dette er imidlertid svært at spotte på tematisk plan, bortset fra andet kapitel, hvor hovedpersonen og fortælleren er Fias lillebror Inuk, som i sin mailudveksling med eks-veninden Arnaq skriver: "Du er selv ansvarlig for dine handlinger. [...] Hold op med al den selvmedlidenhed, for det er ikke synd for dig." (ibid.:67-68) og dette udsagn afsluttes med den senere hyppigt citererede og diskuterede sætning: "Enoguh of that post-colonial piece of shit." (ibid.:68)

Fra sin diskursive position forholder HOMO sapienne sig til den etablerede fortælling om det ulige magtforhold mellem Danmark og Grønland, men den er langt fra at placere grønlænderne i offerrollen. I stedet for synes Inuks udsagn, når tolket metonymisk, at være en opfordring til, at grønlændere bliver agenter i deres egne liv. Med Leela Gandhis ord, fremsiger HOMO sapienne ,a counter narrative to the postcolonial counter-narrative" (Gandhi, 1998:166) ${ }^{9}$. Men er det det eneste budskab relateret til det postkoloniale, der kan læses ud af romanen? Her bruger jeg med viljeverbet "læse", som lægger vægt på modtagerens aktive rolle $\mathrm{i}$ at afkode romanens flertydelige betydninger.

${ }^{9}$ Gandhi forklarer termen på følgende made: “[...] perhaps what postcolonial literature needs is a properly romantic modality; a willingness to critique, ameliorate and build upon the compositions of the colonial aftermath. It is possible, in other words, to envision a transformed and improved future for the postcolonial nation." (Gandhi, 1998:166). 
"Du ved godt, at jeg aldrig følte mig hjemme deroppe, og jeg har besluttet mig for at flygte." (53) - således forklarer Inuk sin søster Fia motivationen bag sin flugt til Danmark. Inuk er flygtet fra Grønland for at lede efter sit rigtige hjem og dermed genfinde sig selv (som skabsbøsse). Når man sammenstiller denne tråd med hovedpersonerne i dansk grønlandslitteratur, både ældre og nyere af slagsen, opdager man en slående lighed mellem Inuk og de, som litteraturforskeren Ebbe Volquardsen meget passende kaldte "patologiske eskapister" (Volquardsen, 2014). Når Grønland traditionelt har været danskernes "tilflugtssted for utilpassede eksistenser" (Thisted, 2003:38), overtages denne rolle nu af det tidligere centrum, dvs. Danmark, som af Inuk - en flygtning fra den tidligere periferi $-\mathrm{i}$ begyndelsen opfattes som frihedens land i modsætning til det grønlandske "fængsel". Med tiden viser det sig, at snarere end frihed, som Inuk savnede i sit hjemland, præges hans eksil af ligegyldighed med ham og hans problemer, og Danmark bliver aldrig den farverige kulisse for Inuks identitetssøgning, som Grønland var for protagonisterne i de danske romaner. På trods af dette lykkes det for Inuk at finde sig selv, og romanens brug af den omvendte (post)koloniale trope fastslår Grønland som det diskursive centrum i fortællingen om dansk-grønlandske relationer.

Men det, som man som romanens læser, der er på jagt efter mulige postkoloniale betydninger eller strategier, bemærker først - undtagen Inuks rejse til Danmark og hans knappe kommentarer om sit manglende tilhørsforhold dertil - er det totale fravær af det danske på romanens tematiske plan. Det er så godt som næsten visket ud og bortset fra sproget, som romanen (dens danske version) er skrevet $i$, er der ellers ikke nogen spor af Danmark eller danskere. Det kan ikke udelukkes, at de mennesker, som hovedpersonerne omgås i romanuniverset, kan representere andre nationaliteter end den grønlandske, men det nævnes bare ikke. Dette fravær er meget sigende og bekræfter det, som Thisted siger om nutidig grønlandsk litteratur, at den skriver det danske $u^{10}$. Den gamle koloniale trope, der gik ud på at "udviske" de koloniseredes historie, sprog og kultur (Slemon, 1987:11), er her vendt om og brugt som en strategi til at fremhæve det, som kortfattet, præcist og emfatisk, udtrykkes af figuren Habakuk i Kim Leines Profeterne $i$ Evighedsfjorden: "[det] her er vores land!" (Leine, 2012:253). Der er slet ikke tale om en offerrolle, og heller ikke om en migrantposition - Grønland er grønlændernes land, som navnet Kalaallit Nunaat egentlig betyder, og selv om det ligger til forhandling, hvem der er omfattet af termen "grønlændere", efterlades der ikke nogen tvivl om, at det er dem, der er subjekter i deres egne fortællinger.

Inde fra romanens paratekst lyder der dog en 'spøgelsesagtig' stemme, der minder læseren om, at det postkoloniales tid måske ikke helt er forbi. Selve

${ }^{10}$ Oplæg om "Grønlandsk litteratur" ved arrangementet "Nye fortællinger fra Grønland den grønlandske kulturrevolution", Århus, ARoS, 21.05.2017. 
romanteksten indledes med et forord af den danske forfatter Mette Moestrup, der ved siden af den grønlandske digter og multikunstner Jessie Kleeman havde været underviser på en skriveworkshop, hvor de 10 udvalgte deltagere $\mathrm{i}$ konkurrencen "Allatta!" skulle finpudse deres noveller. Forordet begynder med ordene: "Det er altid spændende, når et nyt forfattertalent debuterer." (Moestrup, 2014:9), og senere fortæller Moestrup om sine forventninger til romanen, og sit første møde med Korneliussen, hvor hun takket være sin "bipper i maven" allerede kunne fornemme, at "der er talent på færde" (ibid.:10). Til sidst forklarer hun udførligt romanens mange litterære kvaliteter, bl.a. at "[d]et er et raffineret grundgreb ved HOMO sapienne, at de fem hovedpersoner er fortællere på skift i de fem kapitler, som alle bærer sangtitler" (ibid.:11). Selv om er de svært at benægte de gode intentioner med forordet, kan man ikke undlade straks at få associationer med den koloniale periode og den første grønlandske roman skrevet af Mathias Storch (Sinnattugaq, 1914 / En grønloenders drøm, 1915), der udkom på dansk med Knud Rasmussens rosende forord (Rasmussen, 1915). Selv om Moestrups forord blev skrevet 102 år senere, er den paternalistiske tone heller ikke til at tage fejl af her. Det er som om den 'unge' grønlandske litteratur stadigvæk har brug for et godkendelsesstempel fra sin 'voksne' danske formynder, og at kvalitetsbedømmelsen sker efter dennes målestok ${ }^{11}$.

\subsection{DET POSTNATIONALE}

Postkoloniale teoretikere er generelt enige i, at postkolonial litteratur / migrantromaner per definition er "inaccessible $[\ldots]$ to the possessive prose of cultural nationalism", fordi "all postcolonial / migrant texts are invested with radically subversive energies" (Gandhi, 1998:153-154). Bhabha forklarer det på den måde, at litteratur skrevet af postkoloniale forfattere "disturb those ideological manoeuvres through which "imagined communities" are given essentialist identities" (Bhabha, 1990:300). Det betyder dog ikke nødvendigvis, at romaner skrevet af forfattere fra tidligere koloniserede lande fornægter nationerne deres eksistens, men rettere at de i stedet bliver problematiseret og forhandlet i denne litteratur. Det er også Elisabeth Oxfeldts forudsætning for hendes definition af postnationalitet, der ifølge litteraturforskeren kendetegner en stor del af nordisk litteratur. Oxfeldt nævner fire forskellige undergenrer inden for postnationale romaner, hvoraf i nærværende kontekst især én er interessant: den "nationskorrigerende". "I denne romanen" forklarer Oxfeldt "anses nasjonen som ferdigbygget - dens eksistens tas for gitt - men forfatteren føler at nasjonen er kjørt ut på feil spor hva angår holdninger, verdier og den

${ }^{11}$ Moestrups forord mødte også skarp kritik af danske anmeldere, fremlagt af bl.a. Klaus Rothstein i Weekendavisen fra 28.11.2014 (Rothstein, 2014). 
rolle man spiller internasjonalt." (Oxfeldt, 2012:16) Formålet med dette afsnit af analysen er at undersøge, på hvilken måde HOMO sapienne korrigerer de etablerede fortællinger om den grønlandske nation og om der eventuelt bliver foreslået nogen nye i stedet for. I den sammenhæng er det igen romanens andet kapitel, der tiltrækker sig mest opmærksomhed, fordi et af hovedtemaerne i Inuks fortælling er hans forhold til den dominerende diskurs om grønlandskhed, som fremstilles på følgende måde:

Man er grønlænder, når man er født og opvokset i Grønland.

Man er grønlænder, når man er med til at udvikle sit land.

Man er grønlænder, når man taler sit sprog.

Man er grønlænder, når man følger med i sin kultur.

Man er grønlænder, når man respekterer sine forfædre.

Man er grønlæder, når man elsker sit land.

Man er grønlænder, når man er stolt over sin nationalitet.

Man er grønlænder, når man føler sig grønlandsk. (Korneliussen, 2014:65)

Denne hyperpositive definition af det grønlandske skrevet på selve nationaldagen (21. juni) bliver allerede fra kapitlets begyndelse konfronteret med en mareridtsagtig vision af Grønland som et fængsel fyldt med levende døde - et rigtigt 'zombieland" ${ }^{12}$, "det rådnede mug" (ibid.:53). Det er ikke en realistisk beskrivelse, men en metaforisk gengivelse af det mørke, som Inuk gemmer i sit indre. Senere skriver han: "[J]eg er flov over at være grønlænder" (ibid.:56), og underskriver to af sine indlæg med henholdsvis "Ham, der ikke vil være grønlænder" og "Greenlander by force". Mod kapitlets afslutning bliver læseren klar over, at Inuks raseri mod Grønland og grønlændere først og fremmest skyldes det faktum, at han føler sig uretfærdigt behandlet og forrådt af sin fortrolige veninde Arnaq, så hans raseriudbrud kan lige så godt være en projektion af hans vrede oven på hele det grønlandske samfund. Vrede, der når sit højdepunkt netop på Grønlands nationaldag, som for Inuk er en passende dato til at forklare en og alle, "[h]vad det i virkeligheden er at være grønlænder" (ibid.:65):

Man er grønlænder, når man er alkoholiker.

Man er grønlænder, når man banker sin partner.

Man er grønlænder, når man mishandler børn.

Man er grønlænder, når man er blevet forsømt som barn.

Man er grønlænder, når man har selvmedlidenhed.

Man er grønlænder, når man har lavt selvværd.

Man er grønlænder, når man har vrede i sig.

Man er grønlænder, når man lyver.

12 Dette er også, hvad en anden grønlandsk forfatter, Sørine Steenholdt, kaldte sin roman, der udkom året efter HOMO sapienne (Steenholdt, 2015). 
Man er grønlænder, når man har store tanker om sig selv.

Man er grønlænder, når man er dum.

Man er grønlænder, når man er ond.

Man er grønlænder, når man er homo. (ibid.:65-66)

Som det er blevet konstateret før, må man dog være opmærksom på, at alle de negative ting, som Inuk forbinder med det at være grønlænder, også indgår i hans anklage rettet mod Arnaq. Som læsere kommer vi derfor i tvivl om, hvorvidt det i virkeligheden er en kritik af nationen eller Inuks personlige kritik af veninden, som har svigtet ham - sandsynligvis begge dele, og mere til, for når det er "en løgner", der udtaler sig, kan man aldrig være sikker. Især i lyset af Inuks senere bekendelse: „Jeg har forstået, at grønlænderne ikke er skyld i, at jeg er flygtet fra Grønland. [...] Jeg har forstået, at jeg er ansvarlig for mig selv." (ibid.:71). Handler denne kritik så i virkeligheden ikke om Inuk selv og hans frygt for at blive diskrimineret på grund af sin fortrængte seksuelle orientering?

Et sted i romanen antydes rigtigheden af en sådan fortolkning. Også på nationaldagen skriver Inuk en parafrase af de første strofer i den grønlandske nationalsang Nunarput utoqqarsuanngoravit (Vores land, du er blevet celdgammelt, 1916): "Vores land, du er blevet ældgammelt, gå til fjeldet og kom aldrig tilbage. Hold op med at være så skide højtidelig, og tag dine rådne børn med dig." (ibid.:66) Problemet er imidlertid, at Inuk som homoseksuel regner sig selv til landets "rådne børn", men bliver ved med at fortrænge det, indtil han til sidst bekender sig til Fia. Den dag, han har fundet sit 'hjem' ved at have fundet sig selv, beskrives af ham som "Den sidste dag" (ibid.:74). Denne overskrift indikerer, at han er klar til at komme hjem til Grønland, hvor han trods alle sine forbehold hører til.

Inuks eksplicitte kritik af Grønland og grønlændere er dog ikke det eneste element på tematisk plan, der gør, at romanen kan regnes som nationskorrigerende. I forbindelse med litterære analyser af det nationale nævner Oxfeldt køns- og familiemetaforer, som kan læses politisk (Oxfeldt, 2012:23) ${ }^{13}$. En nærmere analyse af kønsrelationerne i HOMO sapienne viser, at de ved at modsætte sig den heteronormative diskurs artikulerer en mere inkluderende fortælling om det nationale fællesskab. Som en decideret kærlighedsroman, hvor hovedpersonerne dog kun repræsenterer seksuelle mindretal, udfordrer romanen den nationalromantiske familiemetafor associeret med nationen som et "naturligt" etnisk fællesskab, og foreslår i stedet for en anden forestilling om nationen som et fællesskab baseret på statsborgerskab (Oxfeldt, 2012:25). Dette modsætter sig igen den etablerede skematiske fortælling om den grønlandske nation som etnisk defineret, en idé, der blev

${ }^{13}$ For eksempel det, at en mand og en kvinde forelsker sig i hinanden, kan fungere metonymisk og pege på national konsolidering (Oxfeldt, 2012:24). 
direkte hentet i Danmark og omplantet i den grønlandske muld i starten af 1900-tallet (Thisted, 2013:232). Man kan tilføje, at den nye forståelse af nationen, som HOMO sapienne efter min mening peger på, er meget lig den, som den internationale markedsføringsplatform "Branding Greenland" baserer deres kampagner på (Thisted, 2013:231), eller som kunstneren Julie Edel Hardenberg italesætter i sine værker (bl.a. Hardenberg, 2005). Som en forfatter, der tilhører den yngre generation af grønlændere, er Niviaq Korneliussen således med til at forme de nye fortællinger om grønlændere og deres identifikationsmodeller, der er opstået i det 21. århundrede.

\section{DET GLOBALE}

På baggrund af ovenstående analyse kan man slå fast, at HOMO sapienne ikke hører til den transkulturelle litteratur, som med Ottomar Ettes ord kan defineres som "literatures without a fixed abode, litteratures that evade attempts at clear territorialisation" (Ette, 2003:13) ${ }^{14}$. Selv om der overskrides bestemte, snævre og ekskluderende fortællinger om det grønlandske, findes der ikke nogen form for transcenderet national identitet. Hvis man dog flytter opmærksomheden fra det tematiske til det formelle plan, opdager man en udtryksrigdom, der beviser, at globaliseringen for længst har slået rod i Grønland. I det følgende vil jeg benytte mig af en metode foreslået af Elisabeth Oxfeldt, der i korthed går ud på at "perspektivere det nasjonale internasjonalt" for at bevise, at nationale fortællinger opstår i en global kontekst, og derfor skal de læses på tværs af kulturer og nationer (Oxfeldt, 2012:29). Inspireret af Oxfeldts sammenstilling af de nordiske nationsfortællinger med populære vestlige genrer vil jeg gerne undersøge, hvordan HOMO sapienne både sprogog strukturmæssigt trækker på globale tendenser inden for narrative strategier, hvilket resulterer i en hybrid udtryksform på tværs af forskellige medier og genrer.

Værket, jeg har tænkt mig at sammenligne Korneliussens roman med, er den norske netdramaserie SKAM (2015-2017), der ikke kun har opnået en enorm popularitet blandt sin oprindelige målgruppe, dvs. den norske gymnasieungdom, men den er blevet kendt og fulgt af seere verden over. Den er produceret af NRK P3 og der er i alt udsendt fire sæsoner, hvoraf hver enkelt handler om én elev på Hartvig Nissens Skole i Oslo. Jeg har valgt at sammenligne HOMO sapienne med netop SKAM for at kortlægge begge værkers brug af lignende tværæstetiske midler, der trækker på den globaliserede kulturs nye kommunikations- og udtryksformer.

${ }^{14}$ Arianna Dagnino beskriver "transkulturel litteratur" som "works that, together with their authors, are intrinsically border crossers, are able to go beyond the limits of any one culture or national/ethnic landscape" (Dagnino, 2013). 
Første tydelige overskridelse af romanens enerådende status som litteratur er dens brug af musikmediet: hvert af de fem kapitler begynder med en titel på en engelsksproget sang sunget af verdenskendte popmusikere: Joan Jett and the Blackhearts, Foo Fighters, P!nk, Rihanna og Greg Laswell. Ud over at spille en vigtig rolle med hensyn til romanens komposition, citeres sangteksterne direkte i de enkelte kapitler - deres ord hjælper nemlig de unge hovedpersoner til at italesætte det, der ellers forekommer dem uudsigeligt. Som i sidste kapitel, da Fia og Sara endelig forenes, og romanen slutter på følgende vis:

Forårets nat er stille. Nattens lys er mild. Luften er frisk, og jeg stiller mig foran Fia. Jeg kigger på hende. Hører hende. Rører hende. Kysser hende. Jeg vil tilbringe min tid med hende. Jeg føler hende. Jeg elsker hende.

"Crimson \& Clover," siger jeg til hende.

„Over and over," svarer hun mig.

What a day to be alive, tænker jeg.

\subsection{And to begin breathing}

\#whataday (Korneliussen, 2014:178)

Bortset fra det, at sangteksterne citeres direkte i romanteksten, er de også til stede i parateksten på bogens sidste side i form af hyperlinks til YouTubekanalen, hvor læseren kan lytte til de konkrete udførelser. Dette gør, at musikken er repræsenteret i romanen som et selvstændigt medium og udfylder en lignende funktion som lydsporet i filmiske fremstillinger, hvor musikkens rolle er at fremhæve den særlige stemning, gengive personernes følelsesliv eller direkte at supplere handlingstrådene med nye dimensioner. På samme vis som Saras sang og guitarspil for Fia i romanens slutscene i kapitel 1 indikerer teenagepigen Nooras sang og guitarspil for skolekammeraten William, at der er ved at ske noget mellem de to, hvad vi som læsere / seere lynhurtigt opfanger. Det er simpelthen måden, ungdommen kommunikerer på, på tværs af landegrænser, sprog og kulturer.

Som det allerede fremgår af ovenstående citat samt af de føromtalte passager i romanen, er sproget, personerne kommunikerer på, karakteriseret ved hyppig brug af engelske ord og sætninger, og det gælder generelt ikke kun citaterne fra sangteksterne. Det samme kan bestemt siges om SKAM, hvor det ofte er naturligt for personerne at svare på engelsk i stedet for norsk, og deres brug af modersmålet bærer tydeligt præg af det engelske. Hvad mere er, også det danske eller det norske sprog $\mathrm{i}$ henholdsvis romanen og serien er noget særligt: det er sproget, som bruges i nutidens moderne kommunikation via sms, diverse apps (med Facebook Messenger som den hyppigst anvendte) eller bloglignende indlæg med angivelse af dato og / eller klokkeslæt og brug af hashtags. Man bemærker samme kreative blanding af mobile og sociale medier 
i $S K A M$, hvor man ved siden af at vise personernes udveksling af sms'er samtidig med seriens egentlige handling også kan følge med i de fiktive personers gøren og laden på Internettet ved at klikke på deres Instagramprofiler eller blive deres "venner" på Facebook. I begge tilfælde har man altså forsøgt at føre det fiktive univers så tæt på læsernes / seernes egen virkelighed som muligt, og de overraskende lighedspunkter i begge værker tyder på, at når det kommer til det sproglige og kommunikationsformerne, er globaliseringen simpelthen et faktum både i Grønland og i Norge, om man kan lide det eller ej.

Romanens konstruktion viser også mange forbløffende ligheder med serien, ikke kun på grund af de grafisk efterlignede chat- eller sms-vinduer, men først og fremmest på grund af sin polyfone fortællemåde. Hvor hver sæson i SKAM handlede om én bestemt person (Eva, Noora, Isak og Sana), hvis synsvinkel styrede den måde, som handlingen blev præsenteret på, har vi ligeledes i HOMO sapienne at gøre med skiftende - og ligeværdige - synsvinkler hos de fem forskellige hovedpersoner. Når synsvinklen skifter, får læseren / seeren nye oplysninger at vide om de tidligere hovedpersoner, der ikke kun virker supplerende, men også korrigerende $\mathrm{i}$ forhold til den viden, man allerede har tilegnet sig. På den måde får vi et mere nuanceret (og sandfærdigt) billede af hovedpersonen Arnaq, men bliver også klar over, at Inuk, som var fortæller i kapitel 2, havde fortiet vigtige informationer om sin affære med Miki, hvilket først afsløres i kapitel 3, der dermed ændrer vores opfattelse af Inuk og hans uheldige situation.

Sidst men ikke mindst kredser både romanen og serien omkring tilsvarende temaer: det at overvinde sin skam, der nok kan forstås på flere niveauer, men den måske mest åbenbare er at holde op med at lyve for andre og for sig selv og i stedet tale åbent om problemerne. Der kan være flere årsager til skamfølelse, f.eks. ens seksuelle orientering, anoreksi, misbrug eller religion, men - som den satiriske scene i romanen, hvor Sara prøver at google sig frem til svar på sine eksistentielle problemer (ibid.:161-162), viser - de kan kun løses ved at erkende dem og tale åbent om dem med andre. Først da kan personerne være agenter $\mathrm{i}$ deres eget liv, og denne konklusion kan siges at være hovedbudskabet ikke kun hos kunstnerne som Gukki Nuka Willsen Møller (f.eks. i udstillingen "Revner i sjælen"), Bolatta Silis Høegh (i hendes selvportrætter), eller filminstruktøren Otto Rosing (filmen Nummioq (2009) og den nyeste film Tø, der er under produktion), men det kan også spores i DR3's nyeste dramadokumentar Hemmeligheder fra Nuuk (2017), hvor unge grønlændere taler åbent om deres problemer foran tv-kameraet og med deres familier eller kammerater.

Som det er blevet påvist, trækker HOMO sapienne både form- og sprogmæssigt ikke på lokale fortælletraditioner, men den globale verden, der ligger længere væk end Grønland eller endda Danmark. Set i lyset af de tidligere afsnit i analysen kan Korneliussens roman således betegnes som 
udtryk for kosmopolitisk nationalisme ${ }^{15}$, som mode- og designforskeren Marie Riegels Melchior definerer på følgende vis:

Nationalismevarianten kosmopolitisk nationalisme bygger [...] på noget, der ellers opstilles som modsætninger. Nationalisme er baseret på værdier, der hylder det indadvendt nationale og som konsekvens ekskluderer det, der står udenfor. Kosmopolitisme er baseret på værdier, der hylder det internationale og dermed er inkluderende i forhold til det, der umiddelbart kan forekomme fremmed og anderledes. (Riegels Melchior, 235)

Ved at vælge det globale frem for det danske afviser romanen den danske tekstualitets autoritet, men, som det er blevet vist i de tidligere afsnit, udelukker den samtidig nogen form for henvisning til ,autentisk” eller „essentiel” grønlandskhed. Denne konklusion falder i tråd med Thisteds bemærkning om tilstedeværelsen af det globale i grønlandsk kultur: "the global is not an outside entity that encircles the local but is instead embedded in the local" (Thisted, 2013:228), og at takket være udviskningen af det danske, som erstattes med det globale, står man mere frit som grønlænder til at forhandle sin moderne identitet (Thisted, 2011:603). Men i stedet for at være "et formelt udtryk for transcendental hjemløshed" (Frank, 2012:6), navigerer HOMO sapienne mellem det grønlandske og det globale, uden om det danske, og gennem denne horisontale kommunikation udfordrer den de etablerede fortællinger om grønlandsk identitet, nation og det postkoloniale.

\section{KONKLUSION}

Ovenstående læsning af HOMO sapienne har vist, at romanen på flere forskellige niveauer udfordrer de etablerede fortællinger om grønlandsk identitet, nationen og det postkoloniale. Korneliussens fremstillinger af grønlændere underminerer de fastlåste versioner af grønlandskhed, som fremmes af hegemoniske grupper i samfundet, og hun tilbyder i stedet en anden forståelse af identitet som inklusiv, heterogen og dynamisk. Det betyder imidlertid ikke, at det nationale fornægtes til fordel for et transcendentalt, transkulturelt rum - tværtimod er det stadigvæk til stede, selv om fortællingen om det nationale på mange punkter bliver korrigeret og overskredet. Endelig tyder romanens tydelige vending mod det globale frem for det danske på, at der er opstået et alternativ til den dansk-grønlandske relation og at de postkoloniale fortællinger er ved at være ophævet for i stedet at skrive sig ind i den globaliserede verden.

15 Denne betegnelse blev brugt af musikforskeren Andreas Otte i hans oplæg ved arrangementet "Nye fortællinger fra Grønland - den grønlandske kulturrevolution", Århus, ARoS, 21.05.2017. 


\section{LITTERATURLISTE:}

Anderson, B. (2003). Imagined Communities. Reflections on the Origin and Spread of Nationalism. London, New Tork: Verso.

Bhabha, H.K. (1990). DissemiNation: time, narrative, and the margins of the modern nation. I: H.K. Bhabha (red.), Nation and Narration (291-322). London, New York: Routledge.

Bryld, T. (2002). Hjemmestyrets børn - årgang '79. Nuuk: Atuakkiorfik.

Dagnino, A. (2013). Global Mobility, Transcultural Literature, and Multiple Modes of Modernity. Transcultural Studies 2, 130-160. DOI: http://dx.doi.org/10.11588/ts.2013.2.9940.

Edel Hardenberg J. (2005). Den Stille Mangfoldighed/Nipaatsumik Assigiinngisitaarneq/The Quiet Diversity. Nuuk: Milik Publishing.

Ette, O. (2003). Literature on the Move [Literatur in Bewegung, 2001], oversat af K. Vester. Amsterdam: Rodopi.

Foucault, M. (1999). Sexuality and Power [Sexualité et pouvoir, 1978], oversat af R. A. Lynch. In: M. Foucault, Religion and Culture (115-130). Manchester: Manchester University Press.

Frank, S. (2012). Hvad er migrationslitteratur?. Kritik 203, 1-9.

Frello, B. (2005). Hybriditet: truende forurening eller kreativ overskridelse?. I: A. Scott Sørensen (red.), Kultur på kryds og tvars (88-113). Århus: Klim.

Gandhi, L. (1998). Postcolonial Theory. A Critical Introduction. New York: Columbia University Press.

Hall, S. (1990). Cultural Identity and Diaspora. I: J. Rutherford (red.), Identity: Community, Culture, Difference (222-237). London: Lawrence and Wishart.

Kleist Pedersen, B. (2004). Unge og litteratur - 25 år efter. I: B. Jacobsen et al. (red.), Grønlcender og Global: Grønlandsk sprog, litteratur og medier i 25-året for Hjemmestyrets indførelse (63-94). Nuuk: Ilisimatusarfik.

Korneliussen N. (2014). HOMO sapienne. Nuuk: Milik Publishing.

Langgård K. (2003). Mellem globalisering, nation building og individets dagligdag på godt og ondt. Nordica 20, 263-300.

Leine, K. (2012). Profeterne i Evighedsfjorden. København: Gyldendal.

Moestrup, M. (2014). Forord. I: N. Korneliussen, HOMO sapienne (9-12). Nuuk: Milik Publishing.

Oxfeldt, E. (2012) Romanen, nasjonen og verden. Nordisk litteratur $i$ et postnasjonalt perspektiv. Oslo: Universitetsforlaget.

Pram Gad, U. (2009). Post-colonial identity in Greenland? When the empire dichotomizes back - bring politics back in. Journal of Language and Politics 8, 1, 136-158. DOI: 10.1075/ jlp.8.1.08gad

Rasmussen, K. (1915). Forord. I: M. Storch. En grønlcenders drøm [Sinnattugaq, 1914] (VIIXVIII), oversat af K. Rasmussen. København, Kristiania: Gyldendal Nordisk Forlag.

Riegels Melchior, Marie. (2013). Dansk på mode! Fortcellinger om design, identitet og historie $i$ og omkring dansk modeindustri. København: Museum Tusculanum.

Rothstein, K. (2014). Nuuk Sapiens. Weekendavisen, 28.11.2014. Hentet fra: http://www.rothstein.dk/ 2014/niviaq-korneliussen-homo-sapienne/ (7.01.2018).

Slemon, S. (1987). Monuments of Empire: Allegory, Counter-Discourse, Post-Colonial Writing. Kunapipi 9.3, 1-16.

Storch, M. (1915). En grønlcenders drøm [Sinnattugaq, 1914], oversat af K. Rasmussen. København, Kristiania: Gyldendal Nordisk Forlag.

Steenholdt, S. (2015). Zombieland [Zombiet Nunaat, 2015], oversat af Niviaq Korneliussen. Nuuk: Milik Publishing.

Terpstra, T. (2015). Inuit outside the Arctic: Migration, identity and perceptions. Circumpolar Studies, 10, Groningen: University of Groningen. Hentet fra: https://www.rug.nl/research/ portal/files/23085095/Complete_thesis.pdf(1.01.2018) 
Therkildsen, L., Vahl, K. (red.). (2013) Inuusuttut, Nunatsinni Nunarsuarmilu / Ung i Grønland, ung $i$ verden, oversat af A. Dahl Petrussen et al. Nuuk: Atuakkiortut, NAPA, Milik Publishing.

Thisted, K. (2003). Danske grønlandsfiktioner: Om billedet af Grønland i dansk litteratur. Kosmorama, 49, 232, 32-67.

Thisted, K. (2004). Hvem går qivittoq? Kampen om et litterært symbol eller relationen Danmark - Grønland i postkolonial belysning. TijdSchrift voor Skandinavistiek 2, 25, 133-160.

Thisted, K. (2011). Nationbuilding - Nationbranding. Identitetspositioner og tilhørsforhold under det selvstyrede Grønland. I: O. Høiris, O. Marquardt (red.), Fra vild til verdensborger. Grønlandsk identitet fra kolonitiden til nutidens globalitet (597-637). Aarhus: Aarhus Universitetsforlag.

Thisted, K. (2013). Discourses of Indigeneity: Branding Greenland in the Age of SelfGovernment and Climate Change. I: S. Sörlin (red.), Science, Geopolitics and Culture in the Polar Region, (227-258). Farnham, Burlington: Ashgate.

Volquardsen, E. (2014). Pathological Escapists, Passing and the Perpetual Ice: Old and New Trends in Danish-Greenlandic Migration Literature. I: L.A. Körber, E. Volquardsen (red.), The Postcolonial North Atlantic: Iceland, Greenland and the Faroe Islands (391-417). Berlin: Nordeuropa-Institut der Humboldt-Universität.

\section{Agata Lubowicka}

Uniwersytet Gdański

Instytut Skandynawistyki

Wita Stwosza 51

80-312 Gdańsk

Polska

finalu@ug.edu.pl 